\title{
Dialogic Encounters with Early Readers through Mediated Think-Alouds: Constructing the Transactional Zone
}

\author{
CHRISTIAN W. CHUN \\ University of Southern California
}

EUNICE E. JANG

Ontario Institute for Studies in Education, University of Toronto

\begin{abstract}
In this article, we explore the processes in which four young readers make meanings through dialogic encounters with an interviewer utilizing the think-aloud as a mediator. We believe that these 'mediated think-alouds' act as both a helpful tool to help young readers process and verbalize their interactions with reading texts that may lead to deeper engagements, and a research elicitation tool whose function in analyzing how students talk about texts also acknowledges the interviewer/researcher in the co-constructing of new texts with the reader. In soliciting information about these four readers' problemsolving strategies on reading comprehension questions, the interviewer employed a dialogical and sociocultural model (Bakhtin, 1981; Vygotsky, 1978, 1986) that framed the interactions as a co-constructed reading event (Maybin \& Moss, 1993). Using a Vygotskian sociocultural perspective, we analyze selected extracts of verbal accounts of these elementary school students who were assigned a reading task in the attempt to answer the question: What particular meanings emerged and how were they constructed by the students and the interviewer in their generating of new texts in the process of reading?
\end{abstract}

\section{The Issue}

Textual comprehension involves complex cognitive activities that are continually being shaped by dynamic interactions through mediated cultural practices. Readers constantly draw on their knowledge formed by these practices as they process text, create mental pictures to visualize or synthesize textual information, and evaluate their understandings. Meaningful textual comprehension requires using multiple strategies simultaneously (Baker \& Brown, 1984; Collins, 1991; Johnson \& Afflerbach, 1985; Stanovich, 1986). Yet, much is still unknown about the ways in which young readers engage themselves in the act of reading. One method that has been employed to give researchers partial access into readers' thought processes and their strategies as they read through a text is asking readers to think aloud during their engagement with text.

The expectation of researchers who use the think-aloud method is that they will be able to indirectly observe readers' cognitive processes and strategies by prompting them to talk as they work through tasks (e.g., Cohen \& Upton, 2007; Ericsson \& Simon, 1993; Green, 1998; Swain, 2006a). Readers are typically asked to verbalize either 
concurrently or retrospectively. The standard approach to concurrent verbalization is to ask a reader to state her thoughts aloud while performing a task. In doing so, the reader is not expected to describe or explain what she is doing, but simply verbalizes the information that she attends to while solving the given task. The alternative approach in a think-aloud is to ask the reader to recall her thoughts using some retrieval cues after the task is completed and to provide a verbal report. The use of think-alouds in reading research mainly relies on the notion that in assessing reading comprehension, an 'objective' observer neutrally collects data from the participant (e.g., Ericsson \& Simon, 1993; Gass \& Mackey, 2000). In this scenario, the reader is seen as a solitary agent operating in a decontextualized one-to-one relationship with the text, feeding information to the researcher or assessor. Rather than adhering to this notion of reading as an isolated activity in which talking about a text is regarded as "evidence of prior individual understanding" (Maybin \& Moss, 1993, p. 140) of a singular meaning in the text that exists independently of the reader, we instead view meaning as being constructed and transacted through creation of new texts produced by the reader (and at times the interviewer) during the reading process (Smagorinsky, 2001). As Smagorinsky (2001) argues, "this process of text production conceivably involves additional reflection through which the reader potentially produces further texts. The reader's construction of these new texts is the source of meaning in reading" [italics added] (p. 134).

This alternative view of reading has implications for the traditional use of the think-aloud by not only researchers who are aiming to assess reading comprehension processes but also by classroom teachers who adopt it as a "metacognitive technique or strategy in which a teacher verbalizes thoughts aloud while reading a selection orally, thus modeling the process of comprehension" (Harris \& Hodges, 1995, p. 256). This very modeling of a particular person's comprehension process for the benefit of others ignores the multiple practices readers bring to bear when reading, and in doing so, valorizes a particular way of reading a text that may not resonate with a reader. A teacher's modeling should demonstrate the multiple ways in which more than one meaning can be constructed through textual engagement, which requires metacognitive thinking.

In this article, we explore the processes in which four young readers make meanings through dialogic encounters with an interviewer with a special attention to the think-aloud as a mediator. We believe that these mediated think-alouds act as both a helpful tool to help young readers process and verbalize their interactions with reading texts that may lead to deeper engagements with these texts, and a research elicitation tool whose function in analyzing how students talk about texts also acknowledges the interviewer/researcher in the co-constructing of new texts with the reader.

In the following case studies of the four young readers, the interviewer, in soliciting information about these readers' problem-solving strategies on reading comprehension questions, utilized a dialogical and sociocultural model (Bakhtin, 1981; Vygotsky, 1978, 1986) that framed the interactions as a co-constructed reading event (Maybin \& Moss, 1993). Analyzing selected extracts of verbal accounts of four elementary school students who were assigned a reading task from a Vygotskyian sociocultural perspective (e.g., Smagorinsky, 2001, Swain, 2006b, Vygotsky, 1978; 1986), we attempt to answer the question: What particular meanings emerged and how 
were they constructed by the students and the interviewer in their generating of new texts in the process of reading?

\section{Dialogic Engagements with Texts}

Drawing on the work by Street (1984) and Heath (1983), Maybin and Moss (1993) observe that "by concentrating on reading as a social event, anthropologists have highlighted that individuals' interactions with texts are often mediated through oral language practices" (p. 138). These oral practices are more than just commenting on a passage; they in fact constitute dynamic and interactive sociocultural formations in which learning is activated and constructed (Vygotsky, 1978). Dialogue, as conceived by Vygotsky, acts as "an important site of learning, mediating between the cognitive development of the individual child on the one hand and their socio-cultural environment on the other" (Maybin \& Moss, 1993, p. 140). Maybin and Moss maintain that it is through dialogue with either peers or adults that children "construct knowledge which is then internalized to become part of their own cognitive development" (p. 140). Thought never occurs alone or in isolation from others; it originates "within social interactions in particular cultural settings" (p. 140).

These insights have direct implications for how we might view reading in particular cultural settings of elementary schools in North America. Rather than seeing it as an isolated activity, Maybin and Moss suggest that reading is "a much more provisional social business...and that the process of collaboratively checking out and constructing meanings through dialogue provides the basis for subsequent individually attributed understandings" (p. 140). Reading in this cultural setting is thus a social event that involves the cultural and literacy practices each reader brings.

In sociocultural terms, literacy practices involved in reading a text do not position learners/readers as "regurgitators of knowledge" (Smith, 2005, p. 330), which reflects a paradigmatic view of learners/readers as "disconnected knowledge processing agents" (James \& Bloomer, 2000 as cited by Smith, p. 330). Instead, viewed through a sociocultural lens, learners/readers are active meaning-makers who, in their engagements with texts, utilize enabling and facilitating interactive practices that draw upon the rich resources of self-activities, others, and their surrounding environments (Smith). These readers are transactional (Gupta, 2004) because they are the ones "who interact with the text to create meaning and enjoy reading" (p. 69). In contrast, Gupta points out that there are other readers who she calls "reduced" - in the sense they are reluctant to read and view the act of reading as painful. However, Smith notes that this distinction is not static since developing a more active role in constructing meaning-making strategies can help lead a former "reduced" reader to become a more actively engaged "transactional" one.

One meaning-making strategy entails collaborative engagement with texts. Drawing on Vygotsky's (1978, 1986) work on language and thought, Swain (2006b) argues that the language mediated process involved in cognitive activities such as reading is "an aspect of learning, and is made visible as learners talk through with themselves or others the meanings they have, and make sense of them" (p. 95). Citing a study by Chi et al. (1994), Swain offers evidence that students who verbalized explanations to themselves after reading each sentence in a science text "developed a more accurate, complete and deeper understanding... and retained that understanding over a longer time" (p. 97) than 
the students who did not talk aloud about the text but instead only read it silently. In processing the dense textual information, these students used spoken language to mediate their interactions with the text, and in doing so, created a "vehicle through which thinking is articulated and transformed into an artifactual form" (p. 97). This artifactual form is termed by Swain as a "coming-to-know-while-speaking phenomenon" (p. 97) that enables us to see how learning takes place.

Viewed from a Bakhtinian lens of multiple voices and perspectives, learning is seen as a continuing dialogue in which student and teacher co-construct knowledge. These multiple voices, or in Bakhtin's (1981) phrase, "heteroglossia," create a site in which "every utterance contains within it the trace of other utterances, both in the past and in the future" (Morris, 1994, p. 249). It is these utterances that contain traces, or even sometimes significant "chunks" of other utterances that are worth examining for its social constructions and meanings. This view of language and its functioning raises several questions that need to be formulated on both a theoretical and empirical level. Why and how was an utterance constructed in a particular way? What actually constitutes "original" thought? Given the context in which Bakhtin was working, it is clear to see one implication of his stance is the rejection of proprietary notions of ideas, thoughts, and language. There cannot be words, or utterances that function independently of other utterances, without constraints, restrictions, histories, or structuring ways to express ontological and epistemological views. These "dialogic overtones" (Bakhtin, 1986, p. 102) of interconnected and interanimated utterances are worth examining for how they "reflect the voices of others, including entire groups, who are not present in the immediate speech situation" (Wertsch, 2006, p. 61).

These voices of others that emanate from students in their particular ways of talking about texts in a classroom are significant in that "different readings and reading positions have material and discursive, social and cultural consequences for readers" inasmuch as "different readings count differently with differential kinds of force and power for individual readers and for interpretive communities" (Smagorinsky, 2001, p. 136). In the classroom, the arbiter who decides the 'official' meaning of a text is most often the teacher. This power differential in who decides what counts as meaning, and who has the authority to judge or consign other ways of reading texts as being less authoritative can have a serious impact on readers who may not possess "the capital to vigorously invoke other conventions that might have authority in other settings" (p. 138). Therefore, it is important to recognize not only the texts that are generated in the act of reading by readers who possess similar ways of talking as the teacher, but also the texts that are generated by readers who may have different cultural practices with regards to a particular reading.

\section{Participants and Data Collection}

\section{Research Design}

The data discussed in this article were collected in the context of a larger study investigating elementary school students' strategy use in literacy and numeracy tasks for diagnostic assessment (Jang, 2009). In the larger study, 37 participants (six to eight students from each of the grades 3 to 6) were involved. The participating students were selected in consultation with their teachers in order to include a wide range of proficiency 
levels. Some of the students participated in both literacy and numeracy think-alouds. The data in this paper are based on interviews from the case studies of four students in Grade 4; three are females and one a male: Sara, Katy, Tammie, and Travis (all are pseudonyms). Their ages ranged between 9 and 10 years old. The first author interviewed the particular students selected for analysis. We had not known each other before, so these interviews were our first encounters. Although this purposeful sub-sampling limited the scope of the data and thus points to the potential limitation of a small sample case study approach, we believe one strength of the small sample case study approach is that it allows us to examine more in depth these individual readers' meaning-making processes.

Sara and Travis are native English speakers, and Katy and Tammie are from bilingual homes. Each session took place at the students' school, which is located in an urban city in Ontario, Canada, and lasted on the average of approximately 25 minutes. The interviews were conducted in a small room in which there was a table and two chairs with the participant and the interviewer facing each other. The instrument that was used to engage students in thinking aloud included two passages (expository and poetry) with five reading comprehension questions for each passage, which were selected from the provincial curriculum-based reading assessment. All the sessions were both video and audio-recorded and transcribed.

Following the think-aloud verbal protocol prepared for the study, the interviewer first asked each participant his/her name, grade, teacher, country of birth, and the primary language(s) spoken at home. Next, the interviewer asked the participant a set of literacy engagement questions to inquire about the participant's interest in reading, reading behavior at home, and media literacy. The procedures for the think-aloud were then carefully explained to the participants, who were assured their answers to the reading comprehension questions were not being assessed for correctness. They were then given a sample question to the following passage as a kind of 'warm-up' practice in verbalizing their reasoning: "Tom was walking to school in the morning because he had missed a school bus. Suddenly, it started to rain. Tom..." The participants were asked to complete the narrative and explain the purpose of this exercise. After this task was completed, the participants then read the two passages. The expository passage is a process description entitled "Popcorn Under Pressure," an account of how popcorn is made, and the second passage is a poem entitled "Flowers and Frost," which describes the flow and rhythms of the seasons.

The larger research study had three individual interviewers following the above procedures. There was a protocol established for the traditional think-aloud for the participating students in the fifth and sixth grade. The traditional think-aloud intends that there are no additional questions other than the ones specified in the research design. The three interviewers were given a standard think-aloud verbal protocol that explained the procedure with some sample probing questions, and there were the inevitable variations among the interviewers. The first author's interviews initially followed this protocol, but with more mediation than the other two interviewers. This was not planned for, nor was it part of the original research design or intent. This occurred most likely due to the first author's extensive teaching experiences, spanning 17 years at the time of these interviews. Specifically, the mediation during the think-aloud interviews presented here emerged out of the first author's pedagogical style, which he employed regularly with his 
students in a sociocultural, dialogic manner. This was reflected in his interactions with the participants despite attempting to adhere strictly to the protocol established. We see this think-aloud process as being different from other research methods that involve interviewing a participant about making sense of text in that the interviewer in this case was doing more than merely interviewing participants about the text: At times, both were involved in co-constructing meanings, and in several cases, the interviewer was actively facilitating the participants' making of meanings rather than merely helping to solicit their input. What follows are the illustrations of the interviewer's mediation helping to co-construct the readings as a dialogic, social event.

\section{Data Analysis}

We started data analysis by reading through the transcripts iteratively and expanded our analysis to video-recordings for a more comprehensive and complex view of how each displayed non-verbal responses that multiplied the communicative and meaning-making effect of their reading 'performance'. To account for these multimodal dimensions of the mediated encounters, we employed a discourse analysis based on the work by Gee (2008), Kress and Van Leeuwen, (2001), and Lemke (1992; 1995). In doing so, we looked at both the verbal discourse generated and the other meaning-making resources such as the participants' body language, gestures, tone of voice, and in the case of one participant, written text on her t-shirt. In examining these other semiotic resources, our analysis acknowledges how these various modes helped to construct the participants' encounters with the text. The basis for our unit of analysis was this interplay among different texts: a t-shirt slogan, the participants' body language while reading, the reading passage, and the interviewer's questions. Our analyses of the data thus helped us understand how the meanings in the reading passage were negotiated, located, coconstructed, and sometimes contested during these mediated encounters. In the next section, we present the results based on the case studies of the four students, which are illustrated by dialogic episodes excerpted from the verbal data. These verbal accounts reflect the children's thinking processes in which they engage in textual comprehension and problem solving, which are further mediated through the dialogic encounters with the interviewer. Their verbal accounts are not completely reconstructed but mediated; thus, we consider the data as mediated think alouds.

\section{Young Readers and Their Meaning Constructions: Four Case Studies}

The four students were not uniform in their approaches to textual engagements. One line of inquiry is to explore how they performed in constructing meanings in particular ways that reflect embodied discourse practices. How might a reader's performativity in discussing a reading be received by teachers who may be predisposed to see one performance as being more indicative of a 'successful' reader? We present four case studies that illustrate young readers' agencies in action as they work through the reading passages while interacting with the interviewer and address how these readers' performances are stylized in their modes of expression. 
Sara

Sara, born in Canada and speaking English as her primary language, 'announces' herself in a confident manner befitting a person presenting herself at a job interview when asked her name. Her self-assured assessment of her own abilities in reading and writing is clearly part of her identity already. While interacting with the interviewer, Sara sat straight up, did not move much, and faced her interviewer squarely. Sara's identity as a good reader is seen in the following excerpt:

Transcript excerpt 1 (underlined sentences are from the reading passages and instruments)

C (Interviewer Christian): OK, great. So, here's just a sample question for us

to practice. So, what is the question asking you to do? Can you tell me what you're thinking? So, can you read this out loud?

$\mathrm{S}$ ( $4^{\text {th }}$ grade, female, Sara): Tom was walking to school in the morning because he had

C: $\quad$ OK.

S: $\quad$ I kind of think um, but that the guy Tom would do for getting to school.

C: $\quad$ OK.

S: $\quad$ And if I were writing a story like this, I would like, think about maybe three different things I could write that would fit in there. And then choose the one I like best.

$\mathrm{C}: \quad \mathrm{OK}$, and do what do you think happens next? In that story?

S: $\quad$ Uh, Tom started running a bit faster so he wouldn't get as wet.

$\mathrm{C}$ : OK. How did you arrive at that answer?

S: Well, because it's kind of like, like that's what most people would do.

C: $\quad$ OK.

S: $\quad$ Like they would if it started to rain and if they didn't have an umbrella they would probably start running.

C: $\quad$ OK.

S: $\quad$ Or put like a magazine over their head.

$\mathrm{C}$ : OK, all right, great. What type of reading is this? Or would you say?

S: $\quad$ Short story.

C: $\quad$ Short story. OK and usually when you read short stories, what do you usually expect when you read short stories?

S: $\quad$ Um, well because they don't have to do a very long stories, the authors, I expect a lot of detail in their writing.

Her utterance, "if I were writing a story like this" in line 9 suggests that Sara actively positions herself as a writing authority in charge. Her first person conditional seems to indicate an active agency in reading texts. This is further evidenced when, instead of merely guessing what might happen next to Tom, she puts herself in the role of a person conversant in literary conventions: "I would like, think about maybe three different things I could write that would fit in there" (lines 9-10). She shows no deference to the story's textual authority in its presentation on the printed page; instead, she adopts the subject position of a hypothetical writer of this text through the use of the first person 
pronoun. She feels confident that she could write a story "like this" one (line 9). Her grasp of the narrative conventions is clear in her assertion that she could think of several scenarios that "would fit in there" (line 10). Her way of interacting with the text is shown in her conceptualization of what "fits" with the narrative. Her answer that Tom would start running is not overly remarkable in its imaginative choice, and in fact is identical to two other students. However, framed within her overall attitude to the text reflected in her comments, her idea of what Tom would do signals her non-deferential stance in relation with the text. Her comment, "choose the one I like best" (line 10), shows she is the one in control of the narrative, the one who can actively construct and determine its storyline. Her own text of narrative agency indicates a stance of being comfortable with narrative conventions and expectations, and a control of the text.

Her familiarity with and knowledge of this text genre is reflected in her answer to the interviewer's question in line 20, "What type of reading is this?" She quickly replies, "short story" (line 21). Her expectations of the genre's conventions are clear: "because they don't have to do a very long stories, the authors, I expect a lot of detail in the writing" (lines 24-25). Again, her identity as a competent reader is indexed here by her expectations of the short story genre - her focus on a crucial element in the construction of short stories suggests an intimate familiarity with this genre.

In the following excerpt, after being reminded again to verbalize her thoughts aloud while reading the two passages, Sara begins reading the introduction of the expository passage on popcorn (underlined below), and then comments on the text:

\section{Transcript excerpt 2}

Sara: It looks like kitchen magic. You take a handful of dried corn kernels, small and hard as ladybugs. Throw them into a hot pan with a little oil, and soon they're jumping, spinning and exploding into shapes like freeze-dried clouds. That's popcorn. Don't forget to put on the lid. But why does popcorn pop? I kind of think, like, it's kind of a little kid thinking about it because they are trying to think about how popcorn pops and because adults probably know that already. So, maybe a five or six year old.

Here is an example that belies the notion of a text possessing a meaning of its own. When asked to share her thought processes as she reads through this passage, Sara does not comment on the meaning of it as an introduction to a scientific process, but instead encodes it as the thoughts of a younger child. This is reflected in her adopting an identity of a much older person, a much more experienced literacy practitioner when she states that "I kind of think, like, it's kind of a little kid thinking about it...maybe a five or six year old" (lines 4-6). Although Sara is in grade 4 and just a few years older than a 6 year old, she does not seem to regard herself as a "little kid" in this instance. More importantly, she interprets the text as an utterance of a "little kid" narrating the process rather than as a science text for elementary school students. Her stance toward the text seems to imply that if she were the writer, her thoughts and languaging of the process would be more sophisticated. Another following excerpt illuminates Sara's literacy agency further: 


\section{Transcript excerpt 3}

1 Sara (S): Where would this text most likely be published? a. in a book of poetry, $b$. in a science textbook, $c$. on the front page of a newspaper, or d. on the editorial page of a magazine. I think it would be in a textbook, because um, a lot of teachers teach about like how liquid goes to gas and how gas goes to solid and that, and this is kind of about that like how the water turns into steam and how popcorn is made. So, it wouldn't really be a in a book of poetry or...

Christian (C): Why not?

S: Well, it's not really a poem; it's more information. And it's not, it's not something that would be in a newspaper because most people know how popcorn is made. And in a magazine, most magazines are not about popcorn.

$\mathrm{C}: \quad$ What are they about in your experience?

$\mathrm{S}$ : Um, magazines? Like there is a bunch of fashion magazines, animal magazines, that kind of thing.

C: $\quad$ OK.

S: And about celebrities. There is some about food, but usually it focuses on like fancy things. Like, um, crème brûlée or something.

$\mathrm{C}: \quad \mathrm{Hmm}, \mathrm{OK}$. Do you like reading magazines?

S: Uh, sometimes it depends on what they are about.

C: $\quad$ OK, well, what kind of magazines do you usually really like to read?

S: Well, I don't really like gossip magazines on like stars or fashion because I'm not really into that stuff, I like, I'm an animal lover and I also ride horses.

\section{C: $\quad$ Oh?}

S: And, I own my own horse so I read books magazines about horses, animals, dogs that sort of thing.

In line 1, Sara reads the fifth and final reading comprehension questions to the expository passage on popcorn. Her statement that the passage would not be found in a poetry book is met by the interviewer's reply of "why not?" in line 7. The interviewer's interactional invocation of a challenge to Sara's response can be seen as an example of the interviewer's mediating style that differs from both the think-aloud protocol and other research methods involving interviewing. In the think aloud, the interlocutor is mainly following a pre-set protocol in the prompts while interviews elicit information from participants. However, here, and in the following exchanges, we would characterize the interactions as a mediated think-aloud because the interviewer departs from the protocol script in mediating certain answers that do more than just elicit information. For example, in line 9, when Sara remarks that "most magazines are not about popcorn," the interviewer, instead of moving on to the next protocol question, made the decision to follow up on this comment by asking, "what are they about in your experience?" The interviewer's choice in departing from the script reflected his interest to see how Sara's literacy practices---reading magazines and her knowledge of magazine genres--connected with her making sense of this particular text. It also facilitated Sara adopting a more self-reflexive approach to talking about the text and its meanings. Taken together, all three excerpted exchanges reflect how, in the departure from the interview protocol, the interviewer mediated the exchange of meanings with Sara. In doing so, this differs 
from merely eliciting information from this participant because the interviewer focuses and expands upon certain answers that can provide insight to how Sara's outside literacy practices may mold the ways in which she makes sense of certain texts.

The interviewer's role here is not one of a disengaged, 'objective' observer, but functions instead as an active, fully implicated participant in co-constructing meanings of poetry books and magazines with Sara. After she describes the various types of magazines in lines 12 and 15, she responds to the interviewer's question on the types of magazines she likes to read by saying in lines 20 through 24 that she doesn't "really like gossip magazines on like stars or fashion because I'm not really into that stuff, I like, I'm an animal lover and I also ride horses." As she was making this statement, Sara gestured to her t-shirt, on which the following text was printed: "I am a girl. I am an athlete. I ride horses. Prepare to EAT MY DUST." This act of meaning-making in her connecting her verbalized words to the printed words on her t-shirt generates an intertext of literacy, life experiences, and cultural practices. This is evident in line 23, when Sara says, "I own my own horse so I read books, magazines about horses, animals, dogs, that sort of thing." The trajectory of the discussion that started from the question on the possible publishing venue for the popcorn passage was detoured by the interactional invoked questions in lines 7, 11, and 19, which created a transactional zone allowing these intertextual meanings to emerge that indexed Sara's embodied, interconnected cultural practices of animal ownership, athleticism, and literacy.

Katy

Katy is a female Canadian-born student who speaks both English and Chinese at home. Wearing a hat pulled low so that the brim covers her eyes when she looked down to read, Katy did not make as much eye contact with the interviewer as Sara did. She positioned herself differently through her talk about the text:

\section{Transcript excerpt 4}

1 Katy (K, female Grade 4, bilingual): Thomas was walking to school in the morning because he had missed the school bus. So he might feel frustrated that he missed the school bus.

Christian (C, interviewer): OK.

K: And Suddenly, it started to rain. So, he might have felt even more frustrated because I think everything he might have felt that everything bad was happening to him.

$\mathrm{C}: \quad \mathrm{OK}, \mathrm{OK}$.

$\mathrm{K}: \quad$ Um, do I write?

C: No that's OK. So what was the question asking you to do [purpose of the exercise]? I mean why did you how did you come up with that answer?

K: I kind of felt that way because if I miss two things or two thing, or three things happened to me in one day, I keep hoping on the first one but if something else happens I kind of almost do that not yet.

C: Hmm.

$16 \mathrm{~K}$ : I just wait to see if anything else happens. And then if something good happens to 17 me I'll be really happy. 
Unlike Sara, who positioned herself as an active agent in charge of writing a narrative regarding the same passage, Katy expresses in lines 10,11, and 14 how she feels: "I kind of felt that way," "I keep hoping," and "if something good happens to me I'll be really happy." Here, she constructs a somewhat passive identity subject position, waiting for events to happen to her, and letting those events shape and influence her emotions. She seems to adopt the imaginary perspective of the character Tom caught in the rain after having missed the bus. In lines 4 and 5 she uses the words "frustrated" and "bad," and then projects the situation of being caught in an unfortunate situation onto herself in line 10, where she says, "I kind of felt that way because if I miss two things or two thing or three things happened to me in one day." Katy uses the first person pronoun as did Sara, but here the effect is different. Katy's "I" indicates a personal experience rooted in emotion, suggestive of a relational experience she brings to the text that in effect re-locates the meaning in ways that are different from other readers such as Sara. Throughout the interview, Katy rarely made eye contact and spoke very softly. Her responses, at times hesitant and tentative, form a set of discourse practices that construct meaning from the same passage in significantly different ways from Sara.

\section{Travis}

Travis was born in Canada and speaks English at home. At the beginning of the interview, he expressed curiosity about the interviewer's audio-recorder, and started to physically examine it. Throughout the interview, while he read passages and answered both the comprehension questions and the interviewer's, Travis continually shifted in his seat, played with his pen, put his hands on his head, leaned back in his chair, and turned his body partly away from the interviewer. In the following excerpt, which picks up right after the passage about Tom being caught in the rain, and the interviewer reminding him again of the think-aloud procedure, Travis is asked to begin reading the popcorn passage. When he started to read the expository passage, he did so silently:

\section{Transcript excerpt 5}

Christian (C, Interviewer): All right, let's start.

Travis (T, male Grade 4): I prefer reading in my head (begins to reads silently).

C: $\mathrm{OK}$.

$\mathrm{T}: \quad$ Is this a story?

C: Huh?

T: $\quad$ Is this a story or just an explanation of why popcorn pops?

C: Well, you tell me.

T: It looks more like an explanation than a story.

C: $\quad$ OK. Are you finished reading already?

T: $\quad$ No. (continues to read)

$\mathrm{C}: \mathrm{OK}$.

T: I'm finished.

C: $\quad$ OK. So what were you thinking about while you were reading?

T: Well, the first thing I started thinking about was why they're explaining popcorn. At first I'm like because it's like a story. 
C: $\quad$ OK, right.

T: $\quad$ Like the Tom one.

C: OK, right. You were surprised?

T: Yeah.

C: Because it was not like a story?

T: Yeah.

Here, Travis seems reluctant to enter into a performative aspect of reading - the read-aloud. While Sara and Katy seemed to enjoy reading aloud the story, Travis prefers reading silently - "in my head" (line 2). He also then seems to be initially confused when he suddenly asks in line 4, "is this a story?" The sample reading of Tom getting caught in the rain seems to have led Travis to expect a reading in the same genre. When confronted with the new text, he is momentarily disconcerted; however he recovers quickly by asking in line 6, "Is this a story or just an explanation of why popcorn pops?" The interviewer, in line 7, does not answer but instead prompts Travis: "you tell me." In line 8 , Travis shows awareness of genre conventions when he says, "It looks more like an explanation than a story." It seems that the sample reading served as a frame of reference for Travis in a way that suggests it may act as an interference in reading a new text witness Travis's comment in line 14, "well, the first thing I started thinking about was why they're explaining popcorn. At first I'm like because it's like a story." To what extent did Travis's expectation of reading a story rather than an "explanation of why popcorn pops" act as a distraction or interference as he attempted to understand what was being communicated to him? He also seems puzzled by another convention that he does not seem familiar with:

\section{Transcript excerpt 6}

Travis (T): What's with all these numbers beside it?

Christian (C): Um.

T: I was wondering what these numbers are for?

C: OK, well what do you think? What um...

T: I don't know. Maybe it's time. Like after five minutes or so or after ten, fifteen, twenty or so to see what's happening.

C: Uh-huh. Could be or could be something else. Not just time, but uh...the space, the lines. Right? OK, so let's answer the questions.

$$
\mathrm{T} \text { : What questions? }
$$

C: $\quad$ OK. Turn the page. OK as you're answering the questions tell us what you're thinking about. OK?

T: $\quad$ What is at the centre of the corn kernel? Uh...

$\mathrm{C}$ : Can you tell us what the question is asking you to do on number one?

$\mathrm{T}$ : $\quad$ What is at the centre of the corn kernel.

$\mathrm{C}$ : OK. Why is the question asking this question?

T: $\quad$ Like what's in the popcorn kernel.

C: OK. Well why?

$\mathrm{T}:$ (Unintelligible)

C: Uh-huh. Why does it want you to know that? 
T: What do you mean why does it want you to know that?

21 C: Well, what do you think the purpose of this question is? I mean, uh...

22 T: To see if you like if you pay lots of attention when you're reading.

$$
\text { C: } \mathrm{OK} \text {. }
$$

$\mathrm{T}$ : (Unintelligible) give me a story to see if I answered the questions correctly while I'm doing the story or not.

$$
\text { C: } \quad \text { OK }
$$

T: Question number two. What is the purpose of the colon in line 11? (Unintelligible) I get it now. That what that is.

$$
\text { C: Mm-hmm. }
$$

T: That's the fifth line, line eleven.

Travis notices the numbers running alongside the text in the side margin at the conclusion of his reading the popcorn passage, and asks the question twice in lines 1 and 3. Rather than simply supplying the answer to him, the interviewer in line 4 encouraged Travis to enter into a dialogic process in which "the text becomes situated among a host of related mediational means through which its meaning potential may be realized: speech genres, social transactions with other readers, cultural schemas, and so on" (Smagorinsky, 2001, p. 141). This interactional move on the part of the interviewer sets into motion a transactional sequence that culminates in Travis' "coming to know" in line 27 - "I get it now" - through his extended interactional encounter with his interviewer. As Smagorinsky notes, "reading is fundamentally relational and dialogic...that is, in dialogue with cultural predecessors" (p. 141). The practices of these cultural predecessors take place within the "great historical destinies of genres" (Bakhtin, 1981, p. 259). Here, within the genre of a reading assessment instrument, the multiple voices of the numbered lines in a text, Travis' puzzled and inquisitive ruminations, and the interviewer's mediating strategy in facilitating the transaction all meet to generate a text of a literacy knowledge that will be necessary for academic success.

That the textual convention of numbered lines attracted his attention requires us to consider this as a legitimate part of reading a text, especially one that is presented as an academic one. On the standardized tests that Travis will undoubtedly take throughout his school career, he will invariably have to refer to numbered lines in the reading sections for question references. He will have to quickly pinpoint these line numbers to ascertain the information he needs to answer the question. All of this cognitive processing is needed to do well on academic standardized tests. A salient question might be: how and when is this particular skill taught in school? Travis here thinks that the numbers refer to a time dimension rather than a spatial dimension. This is an example of how definitions of literacy might come into play whereby the lack of knowledge about a specific textual convention---in this case, numbered lines in an academic text---might serve to categorize or even stigmatize a student who is unfamiliar with this device.

In the above excerpt, Travis' realization of what the numbers posted on the margin mean comes about through his mediated encounter with the interviewer. Travis navigates his way through the intricacies and unfamiliar features of a text by speaking aloud his thought process, which is continually being shaped by his interviewer's dialogic moves. In the above interaction between Travis and the interviewer, they co-construct the roles of student and teacher. Travis carries on a dialogue with both himself and with the 
interviewer, performing his identity role of thinker and learner. To the extent that our voices are never solely our own, but rather form a part of chain of utterances and borrowings (Bakhtin, 1981), this is a small but significant step in Travis's integration of an institutionalized discourse into his performative discourse as student and learner.

\section{Transcript excerpt 7}

1 Travis (T):The text as a whole answers which of these questions? What's that supposed to mean? The text as a whole answers which of these questions? What does that mean?

Christian (C): Well, what do you think the question is trying to get you to do?

T: $\quad$ I don't know like, uh, answer the same question?

C: OK...

T: $\quad$ But I didn't really get the question I'm supposed to be answering is.

C: $\quad$ OK. Uh, the text as a whole, right...

T: Uh-huh.

C: Answers which of the following questions. So, after you usually read something like this popcorn passage.

T: OK.

$\mathrm{C}$ : In your experience...

T: Uh-huh.

C: What do your teachers usually ask you?

T: What you learned from this and about why your ideas and about your ideas. Like what do you think about this and how, and do stuff like, how do you think this is the whole story? Do you think there could there be more?

C: $\quad$ OK and so do you think this type of question is the same?

T: $\quad$ The same as the others?

C: $\quad$ No, the same as what you said before.

T: Oh, I get it.

In this excerpt, Travis reads the fourth question in the popcorn passage. In line 1, Travis verbalizes his thoughts into articulated existence through his twice repeating the question that he initially finds puzzling: "what's that supposed to mean?" Travis seems to be directing his questioning not only to himself, but also to his interviewer. Rather than answering his question directly, the interviewer directs it back to him - "what do you think (it) is asking, trying to get you to do?" Travis uses his interviewer as a resource to help him figure out what the question is asking of him. On the same question, Sara answered the question confidently on her own and without hesitation, and Katy continues on her own after thinking aloud.

In contrast, Travis's asking the interviewer repeatedly about the various parts of the text might be seen by some as being a dependent and weaker reader. However, as Heath (1983) suggests, discourse socializations in various communities vary; these socializations are culturally specific. Travis arrives at his answer not on his own, but through an extended interaction with the interviewer's questions that encouraged reflective inquiry: "And so do you think this type of question is the same?" (line 18). The interviewer assists Travis' reflective inquiry by referring directly to his experiential 
knowledge when he says, "after you usually read something like this popcorn passage...in your experience... what do your teachers usually ask you?" What may appear to some teachers to be a sign of a weaker reader in that Travis needs assistance in helping him to come to a conclusive answer, an alternative position sees Travis skillfully using a resource - his interviewer - to mediate a complex cognitive task. He is the only one who asks about textual conventions and also queries the interviewer's line of questioning. This is interesting because it is possible that Travis may have reacted differently to the power dynamic between himself and the interviewer.

\section{Tammie}

Tammie is Canadian-born and reported that English is the main language spoken at home. Initially, she appeared to be somewhat nervous or frightened to be interviewed; in the first few minutes, she stole glances at the audio-recorder, video-recorder, and looked up at the interviewer repeatedly while she was directed to start reading the passages. At times, she either put her chin on the table or turned her body away when the interviewer asked questions. However, during the course of the interview, she visibly relaxed and seemed to grow more confident in demeanor and in her responses.

\section{Transcript excerpt 8}

1 Tammie (T): Where would this text mostly like to be published [sic] most likely be published? In a book of poetry. In a science textbook. On the front page of a newspaper. On the editorial page of a magazine. In a science textbook. Well because this is sort of like science because it's sort of like having you learn on what popcorn, like how it explodes. It's definitely not a magazine and should definitely not be in the newspaper. Because a newspaper is usually like news and like critical stuff.

Christian (C): OK.

T: $\quad$ Not about science.

C: OK. So, to you what is science then? When you read something how, how, what is it about it that you say OK, this is definitely science or this is not science?

T: Well, because if it is science, then you can tell that it is science because you'll learn like new words that you don't normally use.

C: $\quad \mathrm{OK}$.

T: And it would definitely not be in a book of poetry because it's not like it's not repetitious.

17 C: OK.

18 T: Except it sort of is uh because it uses popcorn a lot.

19 C: Mm-hmm.

20 T: But that's basically what it is. 
In this fifth and final question in the popcorn passage, Tammie already has a clear idea of what constitutes a science discourse in line 5: "if it is science, then you can tell that it is science because you'll learn like new words that you don't normally use." In line 11 , she refers to the process aspect in science indirectly when she points out that the text could not be poetry "because it's not like, it's not repetitious." However, she quickly modifies her comment in line 16 with "except it sort of is, uh, because it uses popcorn a lot." She shows a meta-awareness of how different genres utilize different devices by specifying specific devices such as repetition in poetry, while acknowledging its role in a different context. Her talking through the text in which she not only builds upon her knowledge but also constructs it is indicative of reading as a social, co-constructed event in its mediated processes (Maybin \& Moss, 1993).

Earlier in the interview, Tammie became animated in her telling of an anecdote about how her mother made popcorn the old-fashioned way without a "popper" machine or a microwave - she cooked it in a cooking pot but forgot to put on the lid, which resulted in popcorn being spewed out everywhere in the kitchen. Her engaging anecdote is related to a schemata which is not universal but culturally specific and varied. This highlights the importance of providing a wide range of reading materials that are culturally sensitive and cognitively provocative and will resonate powerfully with diverse readers with diverse experiences in the classroom.

\section{Discussion: Toward a Mediated Think-Aloud}

Smagorinsky (2001) describes his notion of the "transactional zone of meaning construction" (p. 140) as:

During a reading transaction, reader and text conjoin in an experiential space (cf. Faust, 2000). This space provides the arena in which cultural mediation takes place, including the act known as reading. I view this space not as a sealed area connecting two discrete entities but as a dynamic, permeable zone whose instrumentality is a function of culture. The experience that takes place in the space I am describing is thus a joint accomplishment, not just of readers and texts but of the cultural practices through which both have been produced and through which the two become engaged. In this sense, meaning is a function of work conducted among readers and texts rather than between reader and text...The text is thus the focal but not sole tool through which meaning emerges for a reader [italics added]...In an important sense, then, readers do not simply decode texts; rather, they encode texts through activity in the transactional zone. (pp. 141-142)

The traditional think-aloud hopes to 'catch' a glimpse into the reader's mind as she attempts to decipher a singular meaning. The think-aloud relies mainly on assumptions about reading that present a static view of how knowledge is accessed. However, as Nassaji (2002) suggests, it is perhaps more instructive to examine how people talk about what they may or may not know. Although it was not designed or planned for, there were multiple moments throughout these interviews in which what emerged was more than the traditional think-aloud. These think-aloud interviews 
illustrated above showcase Smagorinsky's (2001) transactional zone in their role as an activity tool, and the specific cultural practices of the interviewer in co-constructing meanings along with the reader participants.

Rather than seeing knowledge as an object that is already 'stored' in the mind to be relied on and referenced when reading, a more dynamic paradigm would be to see knowledge as fluid processes being constructed not only in the act of reading, but also in the performative talk about text. We suggest that it is these ways of talking about the texts we read that are the significant bodies of knowledge to which we have access, and that in our talking, we construct, reinforce, try out, and discard ways of presenting knowledge to an audience. The various ways of the four students' presenting knowledge were evident in response to several of the interviewer's questions with them: "What do you usually expect when you read short stories?" "What do your teachers usually ask you?" "Do you think this type of question is the same?" "When you read something, what is it about it that you say OK, this is definitely science or this is not science?" These questions go beyond the traditional think-aloud and thus highlight the need to revisit notions of the think-aloud; indeed, they suggest a specific pedagogy in action. This action, which is evident throughout moments in the interviews, consists of dialogic encounters with readers, and draws upon a sociocultural model in which performative talk about texts coconstructs and distributes knowledge. We have decided to define these moments emerging from these interviews as 'mediated think-aloud' encounters.

Although reading performances are not always directly attributable to specific social factors, and the level of reading engagement is more important than socioeconomic backgrounds in predicting literacy performance (Organisation for Economic Cooperation and Development, 2004), it is important to consider how and why young readers become engaged with particular reading practices in the first place. How are their engagements interconnected with lived experiences? Gee (2008) points out, "literacy practices are almost always fully integrated with, interwoven into, constituted part of, the very texture of wider practices that involve talk, interaction, values, and beliefs" (p. 45). We can infer to some extent the relationship between the particular meanings that emerged from the texts generated from these mediated think-aloud encounters and the lived experiences of the four young readers.

Talk and interaction not only reflect certain values and beliefs but also construct them in the performative act. Sara and Katy used markedly different strategies. Katy stated that Tom "might feel frustrated that he missed the school bus" and that "everything he might have felt that everything bad was happening to him." Katy's commentary on the character and his feelings suggest an interpretative stance toward the scenario. Her stance is different in that she does not place herself in the position of a storyteller; instead, she interpreted the story by framing it in terms of the character's emotions. Travis initially had difficulty in reading test conventions in the form of numbered lines, and the phrasing of particular test questions. However, he was able to employ his own resources in interacting with the interviewer to negotiate the text. Tammie brought a specific social practice to the interview in the form of memory knowledge and relating it to the task at hand.

All of these cases suggest how understandings are not simply constructed from a pre-determined singular meaning that is inherent in the text itself, but rather come into 
existence through an ongoing process of reflection upon the textual generation of talking about the text with either oneself and or with others that ultimately provides the source of meaning. As we suggested above, very often it is the teacher who acts as the arbiter of the 'official' meaning of any given text. This arbitration is usually what counts as meaning. This has consequences of course in that other ways of reading texts may be viewed as being less than acceptable, and as such, young readers whose ways of reading may not map onto the dominant group may be consigned as 'weaker' readers. Thus, it is important that the texts generated by these readers are seen not as an incorrect understanding necessarily, but potentially different cultural practices reflecting different lived experiences.

For students who may not have access to the specific cultural resources that are recognized by the dominant groups in society, mediated think-alouds are a potential teaching tool that can help provide not only a measure of these resources through its dialogic generating of textual resources, but also as a way to value alternative ways of reading. Furthermore, it can help facilitate a deeper engagement with the texts; for example, having students examine and articulate the conventions of a particular genre and engaging with the students in talking about the purposes of the text and its exercises can lead to a greater meta-awareness of how and why these texts are constructed in particular ways. Of course, this does not completely address the potential limitations to the think aloud practice as a learning tool in the classroom, as it is traditionally practiced. If teachers merely rehearse normative readings of texts, and attempt a uniformity of interpretative approaches, this type of think aloud will provide little insight to how our diverse learners make meanings from unfamiliar texts.

Upon examination of the interviews our research group conducted with primary students, it appears that some of these students have more access than others to resources that enable them to construct specific identities of literacy practitioners. These performative identities suggest probable success in contexts of specific literacy practices--those which are recognized and valued in mainstream schools in North America. Their ways of interacting with a text that mediate cognitive tasks should be read within a dynamic of how ways of talking about texts are accorded (or not) a certain 'status' that signifies academic merit, achievement and performance. Reading in school is certainly a social, performative act. Dialogues that emerge from class discussions on the readings are 'performed' utilizing various discourse practices that may not only influence how the performer---the student---is perceived, but also how these meanings are constructed and attributed. The use of mediated think-alouds needs to be explored further for its possibilities and potentialities in highlighting and foregrounding the ways in which the myriad discoursal resources students employ in the classroom are valued or ignored in mainstream schooling.

\section{Conclusion}

Our research analysis has limitations inasmuch as this case study was limited to the four young readers; however, we feel that the potential of mediated think-alouds needs to be explored further. In particular, investigation into how mediated think-alouds might help second language learners in their reading would provide more insight into 
how these readers employ their cultural and linguistic resources in navigating unfamiliar genres and texts.

In a large class, it may be unfeasible for a teacher to be able to use a mediated think-aloud with all the students. One possible scenario might be to pair a stronger reader with a weaker reader and have them dialogue about a difficult reading passage and collaborate on their answers to comprehension questions. Another possible scenario might be for the teacher to model a mediated think-aloud with several students so that the class would begin to get a sense of how to talk about a text in ways that are valued in mainstream schooling.

Mediated think-alouds can be an effective teaching tool due to its potential to help struggling young readers to become stronger readers through the dialogic interactions that promote active engagement with the text. Finally, with the goal of helping students to realize their full potential as learners and thinkers, mediated think-alouds can also function in aiding teachers to better understand how their students engage in acts of meaning making from the texts they encounter. To that end, our study can be useful in helping to understand the complex nature of young readers' reading processes that are shaped and influenced in many ways by their own culture and language.

\section{References}

Baker, L., \& Brown, A.L. (1984). Cognitive monitoring in reading. In P. D. Pearson (Ed.), Handbook of reading research (pp. 353-394). New York, NY: Longman.

Bakhtin, M. (1981). The dialogic imagination. Austin, TX: University of Texas Press.

Bakhtin, M. (1986). Speech genres and other late essays. Austin, TX: University of Texas Press.

Collins, C. (1991). Reading instruction that increases thinking abilities. Journal of Reading, 34, 510-516.

Cohen, A. D., \& Upton, T. A. (2007). "I want to go back to the text': Response strategies on the reading subtest of the new TOEFL. Language Testing, 24, 209-250.

Ericsson, K., \& Simon, H. (1993). Protocol analysis: Verbal reports as data (2nd ed.). Boston, MA: MIT Press.

Gass, S. M., \& Mackey, A. (2000). Stimulated recall methodology in second language research. Mahwah, NJ: Lawrence Erlbaum Associates, Inc.

Gee, J. P. (2003). Opportunity to learn: A language-based perspective on assessment. Assessment in Education, 10(1), 27-46.

Gee, J. P. (2008). Social linguistics and literacies: Ideology in discourses (3rd ed.). New York, NY: Routledge.

Green, A. J. F. (1998). Using verbal protocols in language testing research: A handbook. Cambridge, UK: Cambridge University Press.

Gupta, R. (2004). Old habits die hard: Literacy practices of pre-service teachers. Journal of Education for Teaching, 30(1), 67-78.

Harris, T. L., \& Hodges, R. E. (1995). The literacy dictionary: The vocabulary of reading and writing. Newark, DE: International Reading Association.

Heath, S. B. (1983). Ways with words: Language, life, and work in communities and classrooms. Cambridge, UK: Cambridge University Press. 
Jang, E. E. (2009). Using think-aloud protocols to understand elementary school students' cognitive strategy use in literacy and numeracy tasks. In C. Rolheiser (Ed.), Partnerships for professional learning: Literacy and numeracy initiatives (pp. 3442). Toronto, ON: OISE Initial Teacher Education Program.

Johnson, P., \& Afflerbach, P. (1985). The process of constructing main ideas from text. Cognition and Instruction, 2 (3 \& 4), 207-232.

Kress, G., \& Van Leeuwen, T. (2001). Multimodal discourse: The modes and media of contemporary communication. London, UK: Arnold Publishers.

Lemke, J. L. (1992). Intertextuality and educational research. Linguistics and Education, 4, 257-267.

Lemke, J. L. (1995). Textual politics: Discourse and social dynamics. London, UK: Taylor \& Francis.

Macrine, S. L., \& Sabbatino, E. D. (2008). Dynamic assessment and remediation approach: Using the DARA approach to assist struggling readers. Reading \& Writing Quarterly, 24, 52-76.

Maybin, J., \& Moss, G. (1993). Talk about texts: Reading as a social event. Journal of Research in Reading, 16(2), 138-147.

Nassaji, H. (2002). Schema theory and knowledge-based processes in second language reading comprehension: A need for alternative perspectives. Language Learning, 52(2), 439-481.

Organisation for Economic Cooperation and Development. (2004). Messages from PISA 2000. Paris, France: Author.

Smagorinsky, P. (2001). If meaning is constructed, what is it made from? Toward a cultural theory of reading. Review of Educational Research, 71(1), 133-169.

Smith, J. (2005). Mobilising everyday literacy practices within the curricula. Journal of Vocational Education and Training, 57(3), 319-334.

Stanovich, K. E. (1986). Matthew effects in reading: Some consequences of individual differences in the acquisition of literacy. Reading Research Quarterly, 19, 360406.

Street, B. V. (1984). Literacy in theory and practice. Cambridge, UK: Cambridge University Press.

Street, B. V. (1995). Social literacies: Critical approaches to literacy in development, ethnography and education. London, UK: Longman.

Street, B. (1998). New literacies in theory and practice: What are the implications for language in education? Linguistics and Education, 10(1), 1-24.

Swain, M. (2006a). Verbal protocols: What does it mean for research to use speaking as a data collection tool? In M. Chalhoub-Deville, C. A. Chapelle, \& P. Duff (Eds.), Inference and generalizability in applied linguistics: Multiple perspectives (pp. 97-113). Amsterdam, Netherlands: John Benjamins.

Swain, M. (2006b). Languaging, agency and collaboration in advanced second language proficiency. In H. Byrnes (Ed.), Advanced language learning: The contribution of Halliday and Vygotsky (pp. 95-108). New York, NY: Continuum.

Vygotsky, L. S. (1978). Mind in society. London, UK: Harvard University Press.

Vygotsky, L. S. (1986). Thought and language. Cambridge, MA: MIT Press. 
Wertsch, J. V. (2006). Generalized collective dialogue and advanced foreign language capacities. In H. Byrnes (Ed.), Advanced language learning: The contribution of Halliday and Vygotsky (pp. 58-71). New York, NY: Continuum.

\section{Author Biographies}

Christian W. Chun is an Assistant Professor of Clinical Education in the MAT-TESOL Program at the University of Southern California Rossier School of Education. He has a $\mathrm{PhD}$ in Second Language Education and his research areas include multimodal social semiotic approaches in English language education and mediated discourse analysis.

Eunice E. Jang is an Associate Professor in the Department of Applied Psychology and Human Development at the Ontario Institute for Studies in Education of the University of Toronto. She has a $\mathrm{PhD}$ in assessment, measurement and evaluation and her research interests include cognitive diagnostic assessment in literacy and numeracy, and validity and fairness issues in advancing assessment practices.

\section{Appendix}

It looks like kitchen magic. You take a handful of dried corn kernels, small and hard as ladybugs. Throw them into a hot pan with a little oil, and soon they're jumping, spinning and exploding into shapes like freeze-dried clouds. That's popcorn. Don't forget to put on the lid. But why does popcorn pop. Each kernel of popcorn has a hard outer shell around a pocket of starch. This pocket is called an endosperm, which means "inside the seed." If you could take off the shell, the starch in the endosperm would feel and tastes like a raw potato. There's a lot of water in that starch; in fact, the perfect piece of popcorn is about fourteen percent water. When the popcorn is heated, the water in the endosperm turns into steam. Steam takes up more space than liquid water: the molecules of water in the steam are farther apart and move faster. It's the expansion of the steam that makes popped popcorn so big. A piece of popped popcorn can be forty times as big as a kernel of unpopped popcorn. But the expansion of steam is only half the story. When most things are heated, the water in them just boils away. That's why foods with a lot of water in them, such as mushrooms or tomatoes, usually get smaller when you cook them. Popcorn is different because of the hard shell. The shell keeps the hot steam inside the popcorn like air inside a balloon. The pressure builds up. You can picture the fast-moving molecules of steam pushing and hitting against the hard shell until the shell can't hold them in. Like a balloon, the shell flies apart all at once: it pops. Popcorn is a tasty example of the science of pressure. It may not be magic, but it is magical.

1. What is at the centre of the corn kernel? a. oil, b. starch, c. steam d. potato.

2. What is the purpose of the colon in line eleven? a. to introduce a list, b. to connect an idea, c. to indicate a long pause, d. to separate contrasting ideas. 
3. Read this sentence from line 15: "But the expansion of steam is only half the story." What is the other half of the story? a. The shell gets harder as it cooks., b. Popcorn gets smaller when it is cooked., c. The shell cracks open from the pressure, d. The pot lid keeps the popcorn under pressure.

4. The text as a whole answers which of these questions? a. What is an endosperm? b. Why does steam expand? c. How does pressure make a corn kernel explode? d. How does popcorn cook differently from tomatoes?

5. Where would this text be most likely published? a. in a book of poetry, b. in a science textbook, c. on the front page of a newspaper, or d. on the editorial page of a magazine. 